\title{
Perancangan Sistem Spion Kamera pada Mobil Xenia
}

\author{
Fandi D. Suprianto ${ }^{*}$, Robert William ${ }^{2}$ \\ 1,2 Program Studi Teknik Mesin, Fakultas Teknologi Industri, Universitas Kristen Petra \\ Jl. Siwalankerto 121-131, Surabaya 60236, Indonesia \\ * Penulis korespondensi; E-mail: fandi@petra.ac.id
}

\begin{abstract}
ABSTRAK
Salah satu faktor penyebab utama berbagai kecelakaan kendaraan adalah pengemudi tidak melihat berbagai objek pada titik buta pengemudi. Sebagian besar kecelakaan ini diakibatkan oleh karena pengemudi tidak sadar adanya kendaraan lain. Berbagai upaya telah dilakukan untuk mereduksi titik buta atau blindspot dengan meningkatkan luasan pandang pada spion kendaraan. CMS (Camera Monitor System) telah terbukti mampu mengurangi titik buta dan meningkatkan waktu reaksi pengemudi terhadap perubahan pada spion. Studi ini bertujuan untuk merancang sistem CMS yang mampu mereduksi blindspot dan mengurangi gaya drag. Studi ini menunjukkan bahwa CMS yang dipasang pada spion Daihatsu Xenia menghasilkan luasan pandang yang lebih baik, dengan demikian berhasil mereduksi blindspot, serta bentuk spion CMS yang ramping dapat mereduksi gaya drag secara signifikan.
\end{abstract}

Kata kunci: CMS; luasan pandang; gaya drag.

\begin{abstract}
One of the major causes of vehicle accidents is the driver's inability to see objects in a blindspot. Most of these accidents occur because the driver does not realize that there are other vehicles within the blindspot. Many efforts have been developed to reduce the blindspot by increasing the field of view in conventional wing mirrors. CMS (Camera Monitor System) is proven to reduce the blindspot and increase the driver's reaction time. The aim of this study is to design a CMS which is capable of reducing the blindspot and aerodynamic drag. This study shows that the CMS installed on wing mirrors of a Daihatsu Xenia produces a better field of view, thus successfully reducing the blindspot, and the narrow profile of the CMS cover can reduce drag force significantly.
\end{abstract}

Keywords: CMS; field of view; drag force.

\section{PENDAHULUAN}

Spion pada kendaraan menggunakan cermin cembung maupun cermin datar untuk melihat kondisi sekitar kendaraan yang umumnya tidak dapat dilihat oleh pengemudi. Mengandalkan cermin datar untuk melihat kondisi sekitar kendaraan memiliki keterbatasan berupa titik buta (blindspot). Titik buta merupakan luasan yang tidak dapat dilihat oleh pengemudi melalui cermin. Untuk mengatasi blindspot yang disebabkan oleh cermin datar, cermin cembung digunakan untuk memperluas luasan pandang cermin dan mengurangi blindspot. Penggunaan cermin cembung dapat memberikan pandangan yang lebih luas, namun menyebabkan gambar benda di cermin tampak lebih kecil sehingga hal ini menyebabkan kesalahan estimasi jarak kendaraan, dan kecepatan kendaraan lain [1]. Untuk menghasilkan pandangan yang memadai, spion terletak di luar kendaraan, namun penempatan spion di luar kendaraan dapat mengurangi kualitas gambar yang dihasilkan oleh cermin [2]. Hal ini diakibatkan oleh gangguan seperti kotoran atau tetesan air hujan yang menempel pada kaca kendaraan. Penggunaan ukuran spion yang lebih besar tidak dapat digunakan sebagai solusi untuk mengatasi keterbatasan spion konvensional karena spion berukuran besar dapat menghasilkan gaya drag yang tinggi akibat membesarnya luas area kendaraan.

Selama betahun-tahun, produsen otomotif berusaha untuk mereduksi gaya drag kendaraan dengan membuat bentuk kendaraan lebih streamline dan mengurangi komponen-komponen yang menonjol pada eksterior. Penelitian oleh Otten dan AlObaidi [3] mempelajari efek ukuran dan bentuk spion terhadap gaya drag mobil Perodua Myvi. Pada penelitian ini ditemukan bahwa pressure drag memberikan kontribusi terbesar pada gaya drag kendaraan, perubahan pada bentuk dan ukuran spion 
berpengaruh terhadap gaya drag kendaraan, dan spion berkontribusi terhadap $4.9 \%$ dari koefisien drag kendaraan yang diuji.

Optimasi gaya drag pada spion kendaraan tidak dapat dilakukan dengan cara memperkecil area luasan karena faktor keamanan. Untuk mengatasi permasalahan ini digunakan sistem Camera Monitor System (CMS). Pada sistem ini digunakan sepasang kamera untuk menggantikan kaca spion kendaraan. Informasi dari kamera kemudian ditransmisikan kepada monitor yang dipasang pada kabin kendaraan. Selain dapat mengurangi luasan area spion, CMS diyakini dapat meningkatkan keamanan pengemudi. Analisa terhadap posisi dan ukuran LCD terhadap efektifitas CMS sebagai pengganti spion menunjukkan bahwa penggunaan LCD 8 inch di depan pengemudi memperbaiki waktu reaksi pengemudi sehingga pengemudi bisa mengidentifikasi kendaraan lain hingga 23,6\% jika dibandingkan dengan spion konvensional [4]. Penggunaan CMS dengan field of view yang luas dapat menghilangkan blindspot yang terdapat pada spion konvensional. Selain itu CMS mengurangi gerakan berulang pada kepala pengemudi sehingga mobil dengan CMS memiliki ergonomi yang lebih baik dibandingkan mobil dengan spion konvensional [5]. Melihat besarnya potensi pemanfaatan kamera sebagai pengganti spion kendaraan, penelitian ini bertujuan untuk membandingkan gaya drag yang dihasilkan spion dengan sistem CMS terhadap gaya drag yang dihasilkan spion kendaraan Daihatsu Xenia melalui simulasi CFD serta merancang sistem spion CMS untuk kendaraan Daihatsu Xenia untuk menggantikan spion konvensional.

\section{METODE PENELITIAN}

Penelitian ini membandingkan gaya drag antara spion standar Daihatsu Xenia dengan spion CMS. Gaya drag diperoleh melalui simulasi aliran menggunakan ANSYS Fluent 16.0. Validasi dilakukan dengan membandingkan hasil simulasi profil kecepatan udara yang melintasi Ahmed body dengan hasil eksperimen dari ERCOFTAC. Metode validasi serupa digunakan dalam penelitian lain yang menggunakan pemodelan Ahmed Body [6], sehingga dapat digunakan sebagai acuan dalam proses validasi penelitian ini. Beberapa parameter yang diadopsi dari penelitian tersebut [6] adalah turbulence model k- $\omega$ SST untuk pemodelan turbulensi, parameter slant angle sebesar $25^{\circ}$, kinematic viscosity sebesar $1.5 \times 10^{-5} \mathrm{~m}^{2} / \mathrm{s}$, dan flow velocity sebesar $40 \mathrm{~m} / \mathrm{s}$. Hasil simulasi profil kecepatan dibandingkan dengan hasil eksperimen ERCOFTAC sepanjang sumbu $\mathrm{Z}$ pada posisi $\mathrm{X}=138$ $\mathrm{mm}, \mathrm{y}=0 \mathrm{~mm}$. Dimensi domain yang digunakan adalah 31Lx10Lx7.5L seperti pada Gambar 1 dengan L adalah panjang dari Ahmed body. Error yang dihasilkan pada tahap validasi literatur acuan adalah $17.01 \%$ [6] dibandingkan dengan data oleh ERCOFTAC.

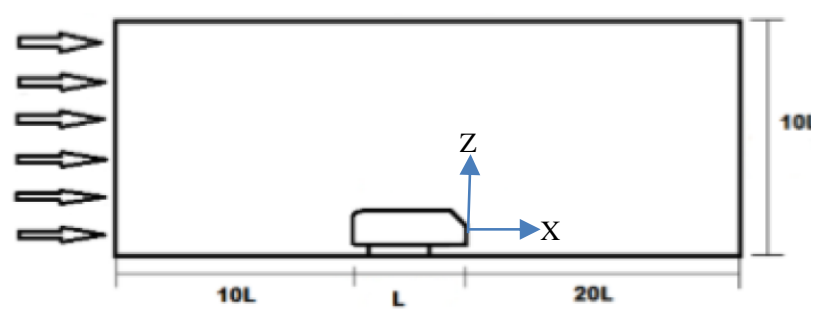

Gambar 1. Ukuran domain simulasi.

Tahap validasi pada penelitian ini adalah mereplikasi dimensi domain, turbulence model yang digunakan pada literatur acuan [6] dan memodifikasi nilai parameter pada ANSYS Fluent 16.0, sehingga diperoleh error sebesar 15\% terhadap eksperimen ERCOFTAC. Perbandingan profil kecepatan hasil simulasi, simulasi oleh literatur acuan [6], dan eksperimen ERCOFTAC ditunjukkan pada Gambar 2.

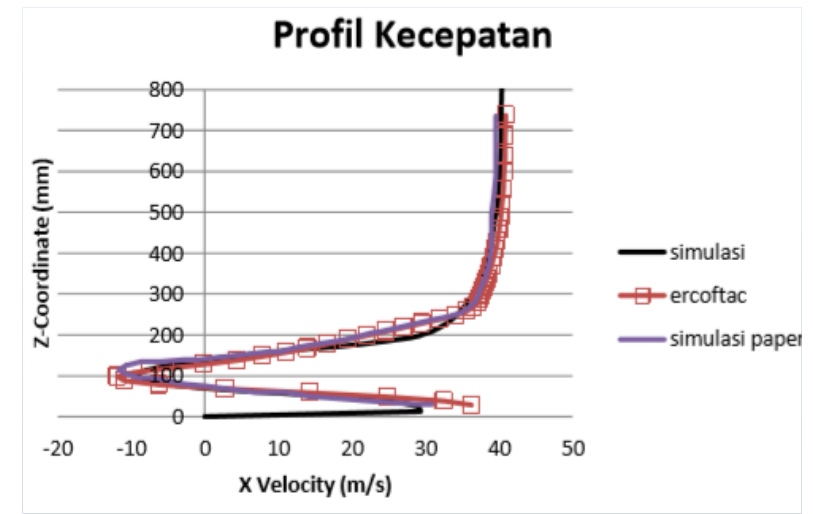

Gambar 2. Perbandingan profil kecepatan hasil simulasi, simulasi oleh literatur acuan [6], dan hasil eksperimen ERCOFTAC.

Model computer aided design (CAD) spion standar Daihatsu Xenia dibuat dengan menggunakan aplikasi desain berbasis komputer Inventor kemudian dilakukan simulasi dengan menggunakan parameter dan rasio ukuran yang telah digunakan pada validasi untuk memperoleh nilai gaya drag. Kecepatan yang digunakan pada simulasi spion adalah 27.7 $\mathrm{m} / \mathrm{s}$. Gaya drag hasil simulasi spion kemudian dibandingkan dengan hasil simulasi model $\mathrm{CAD}$ spion CMS untuk mengetahui besar reduksi gaya drag.

Spion CMS dibuat dengan menggunakan proses $3 \mathrm{D}$ printing agar tidak merubah posisi pemasangan spion pada kendaraan. Alas spion standar Daihatsu Xenia tetap digunakan sebagai alas spion CMS. Spion hasil 3D printing dihaluskan dengan menggunakan dempul dan amplas. Sistem CMS dirancang pada mobil Daihatsu Xenia dengan menggunakan kamera dengan sensor complementary metal-oxide semiconductor (CMOS) untuk menggantikan fungsi kaca pada spion konvensional. Monitor berukuran 7 inci digunakan untuk menampilkan gambar yang diperoleh dari kamera CMOS. Kamera dan monitor dipasang menggunakan daya 12 Volt dari aki kendaraan. Kamera kemudian dihubungkan ke monitor 
melalui kabel video komposit untuk menampilkan gambar. Kamera dipasang pada bagian dalam spion CMS dan ditutup menggunakan akrilik untuk mencegah air masuk kedalam kamera.

Kamera CMOS yang digunakan dapat dirubah jarak fokusnya dengan mengubah lensa yang digunakan. Kamera dengan field of view yang terlalu lebar akan menyebabkan ketidak-nyamanan pada pengemudi. Oleh karena itu diperlukan lensa yang sesuai untuk menghasilkan field of view yang lebih baik dibandingkan cermin spion standar, namun tidak terlampau lebar sehingga menyebabkan ketidak-nyamanan pada pengguna. Untuk menentukan ukuran jarak fokus lensa yang tepat dilakukan pengujian pada 4 jenis lensa yang tersedia di pasaran dengan jarak fokus $2.5 \mathrm{~mm}, 6 \mathrm{~mm}, 8 \mathrm{~mm}$, dan $12 \mathrm{~mm}$ dan dibandingkan dengan cermin spion standar. Kamera diletakkan menghadap area datar pada jarak yang ditentukan, yaitu $116 \mathrm{~cm}$. Lebar area datar (W) yang tercakup dalam field of view kamera diukur sehingga besar sudut field of view (B) dapat diperoleh dari analisa geometri pada Gambar 3 dan dengan menggunakan persamaan di bawah ini:

$$
\beta=2 \tan ^{-1} \frac{W}{2 L}
$$

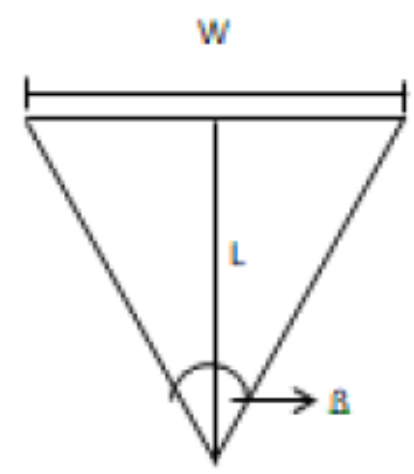

Gambar 3. Sudut field of view ( $($ ) yang dibentuk oleh kamera dan cermin Spion.

Pengujian perbesaran lensa dan cermin dilakukan dengan menempatkan balok kayu dengan tinggi $10 \mathrm{~cm}$ sejauh 1 meter dari titik pengamatan seperti pada Gambar 4. Kamera menampilkan gambar balok kayu. Tinggi balok kayu pada monitor diukur sehingga tinggi benda nyata dan tinggi bayangan benda pada kamera dapat diperoleh. Kedua nilai ini kemudian dibandingkan untuk mengetahui perbesaran.

Untuk menggantikan peran cermin pada spion, kamera harus mampu menyajikan gambar secara instan dengan waktu proses minimal. Keterlambatan informasi monitor (delay) dapat menyebabkan ketidak-nyamanan dan membahayakan pengemudi. Delay sistem CMS yang diperbolehkan adalah kurang dari $200 \mathrm{~ms}$ [7]. Delay sistem diukur dengan menggunakan stopwatch untuk menunjukkan perbedaan waktu yang ditampilkan pada monitor dan stopwatch. Selisih waktu yang dihasilkan oleh monitor dan stopwatch adalah delay yang diakibatkan pemrosesan gambar sistem kamera. Pengujian delay ditunjukkan pada Gambar 5. Delay kamera yang dihasilkan adalah $6.187 \mathrm{~ms}$.

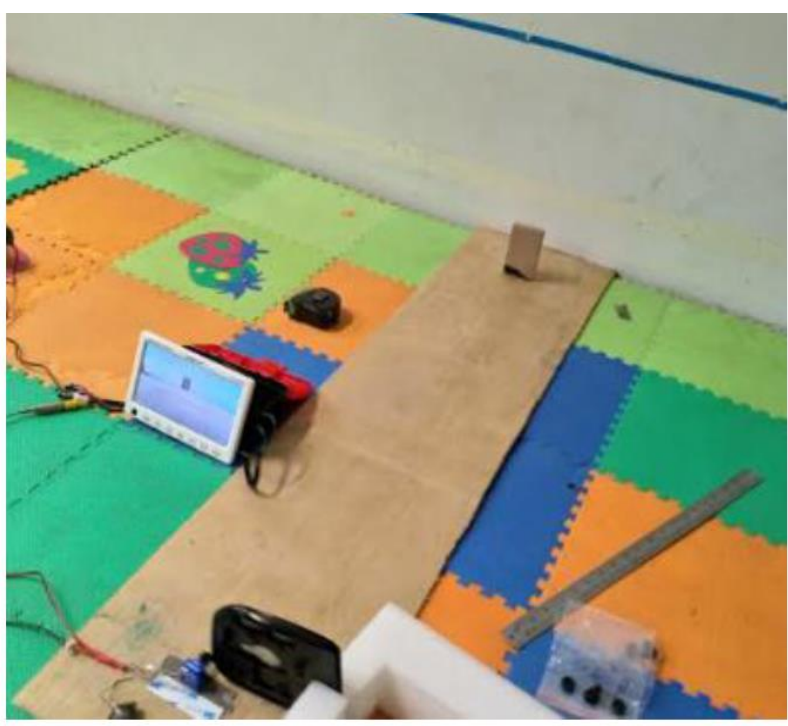

Gambar 4. Pengujian perbesaran lensa dan cermin.

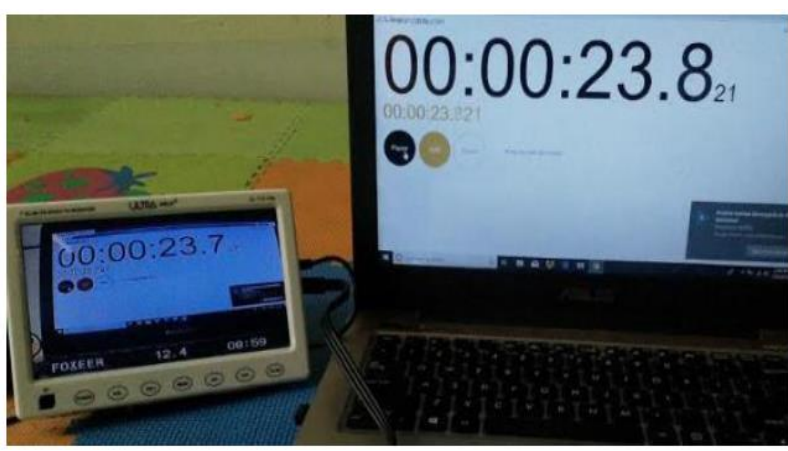

Gambar 5. Pengukuran selisih waktu pada monitor dan stopwatch.

\section{HASIL DAN PEMBAHASAN}

Tabel 1. Hasil simulasi spion standar dan spion CMS.

\begin{tabular}{lcc}
\hline Parameter & Spion Standar & Spion CMS \\
\hline Kecepatan $(\mathrm{m} / \mathrm{s})$ & 27.7 & 27.7 \\
Direction vector & $(1,0,0)$ & $(1,0,0)$ \\
Total drag $(\mathrm{N})$ & 6.714 & 1.438 \\
Drag coefficient, $\mathrm{Cd}$ & 0.516 & 0.479 \\
Frontal area, A $\left(\mathrm{m}^{2}\right)$ & 0.028 & 0.00646 \\
Cd A $\left(\mathrm{m}^{2}\right)$ & 0.014 & 0.003 \\
Convergence criteria, $\varepsilon$ & $10^{-4}$ & $10^{-4}$ \\
\hline
\end{tabular}

Tabel 1 menunjukkan bahwa spion standar menghasilkan gaya drag sebesar $6.714 \mathrm{~N}$ sedangkan spion CMS menghasilkan gaya drag sebesar $1.437 \mathrm{~N}$ pada kecepatan yang sama yaitu $27.7 \mathrm{~m} / \mathrm{s}$. Hal ini diakibatkan karena spion CMS memiliki frontal area yang lebih kecil dibandingkan spion standar. 


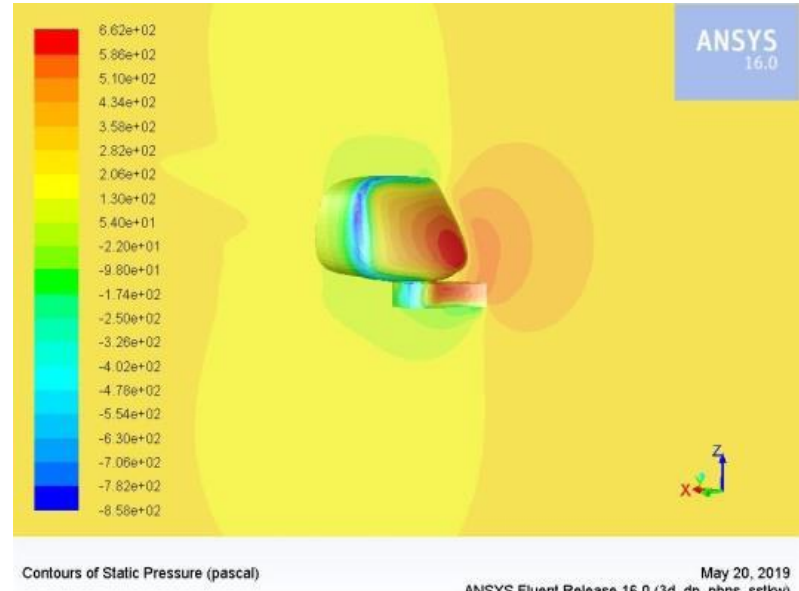

(a)

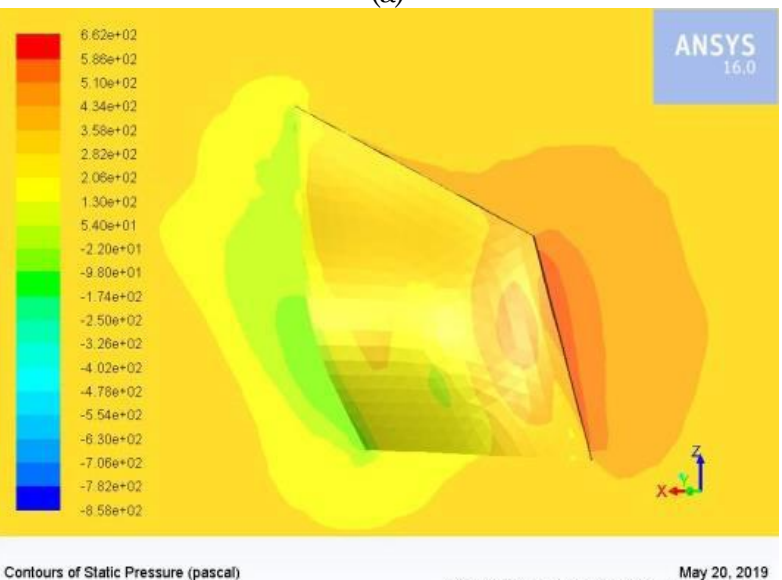

(b)

Gambar 6. Kontur tekanan hasil simulasi: (a) spion standar dan (b) spion CMS.

Titik stagnasi terdapat pada permukaan objek dimana aliran fluida pada titik tersebut adalah nol. Persamaan Bernoulli menunjukkan bahwa tekanan statis mencapai puncak pada kecepatan aliran nol sehingga tekanan statis tertinggi terdapat pada titik stagnasi. Gambar 6 (a) menunjukkan kontur tekanan pada spion standar. Pada gambar ini tampak adanya titik stagnasi pada bagian depan spion. Titik stagnasi pada gambar ini ditunjukkan oleh area berwarna merah dimana besar tekanan statis pada titik ini adalah 662 Pascal. Simulasi spion CMS pada Gambar 6 (b) menunjukkan perubahan lokasi titik stagnasi. Titik stagnasi pada spion CMS terdapat pada bagian depan alas spion yang menyatu dengan bodi spion CMS dimana tekanan statis pada titik ini adalah 479 Pascal. Tekanan maksimum pada spion CMS lebih rendah jika dibandingkan dengan spion standar. Perbedaan tekanan antara bagian depan dan belakang pada spion CMS lebih kecil jika dibandingkan dengan spion standar. Perbedaan tekanan yang lebih kecil ini mengakibatkan gaya drag yang lebih kecil pada spion CMS.

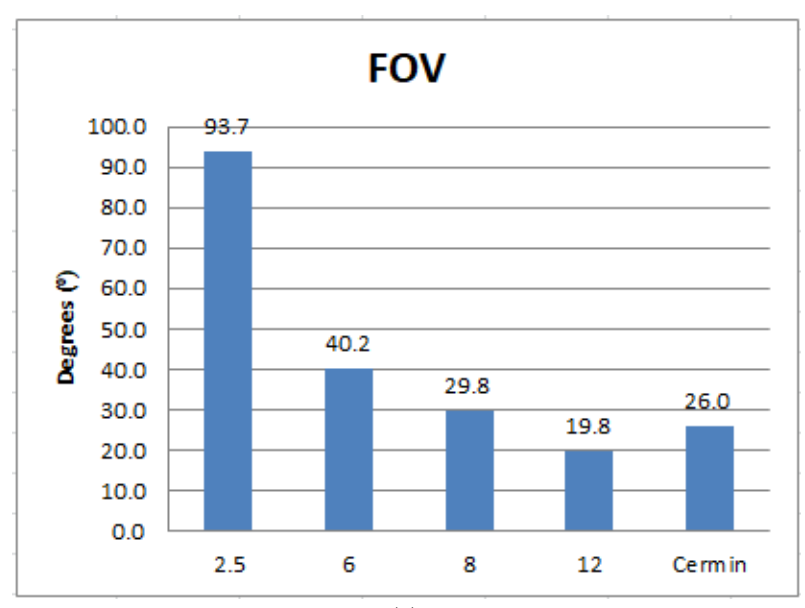

(a)

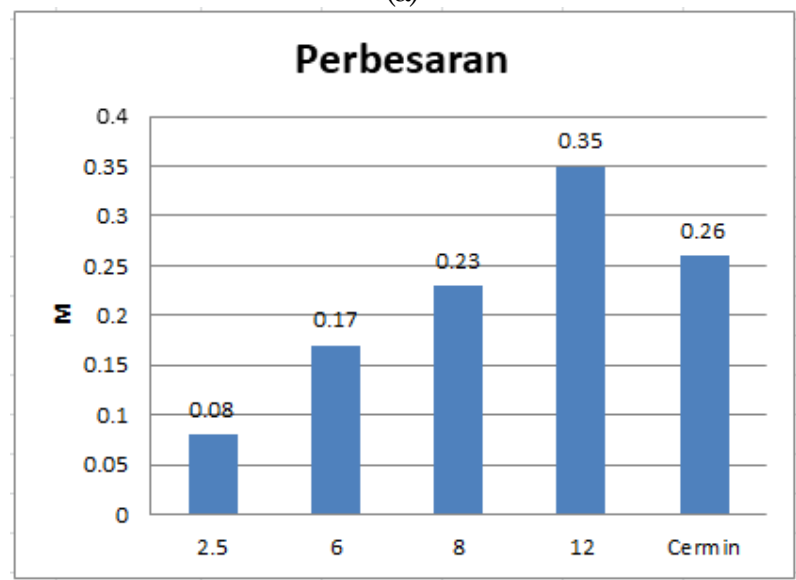

(b)

Gambar 7. Perbandingan FOV dan perbesaran: (a) grafik field of view dan (b) perbesaran yang dihasilkan lensa 2.5 $\mathrm{mm}, 6 \mathrm{~mm}, 8 \mathrm{~mm}, 12 \mathrm{~mm}$ dan cermin spion.

Gambar 7 (a) menunjukkan perbandingan luas area pandang (field of view) yang dihasilkan oleh lensa dan spion. Dapat disimpulkan bahwa semakin kecil jarak fokus sebuah lensa maka field of view yang dihasilkan semakin besar. Cermin spion memiliki field of view sebesar $26^{\circ}$. Agar tidak menimbulkan ketidak-nyamanan pada pengemudi maka digunakan lensa dengan field of view yang lebih luas namun tidak jauh melampaui field of view yang dihasilkan oleh cermin. Lensa $8 \mathrm{~mm}$ memilliki field of view yang mendekati cermin spion, yaitu sebesar 29.8 ${ }^{\circ}$ Dengan menggunakan lensa $8 \mathrm{~mm}$, field of view pengemudi meningkat sebesar $12.75 \%$. Sedangkan pada Gambar 7 (b) semakin besar jarak fokus lensa yang digunakan maka semakin besar gambar objek yang nampak pada monitor.

Agar tidak menimbulkan kesalahan persepsi kecepatan dan jarak kendaraan, lensa yang memiliki perbesaran tidak berbeda jauh dengan perbesaran yang dihasilkan oleh cermin spion dipilih. Lensa 8 $\mathrm{mm}$ memilliki perbesaran yang mendekati perbesaran cermin spion sebesar 0.23. 




(a)
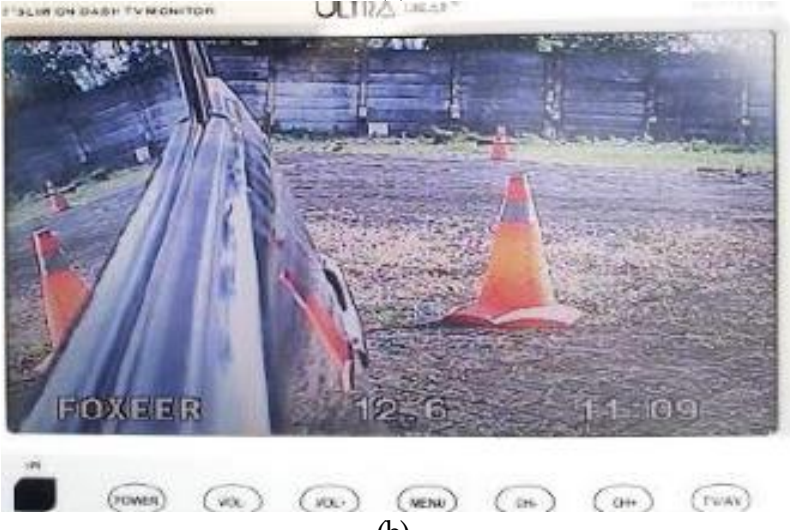

(b)

Gambar 8. Gambar yang dihasilkan: (a) kamera dengan lensa $8 \mathrm{~mm}$ dan (b) cermin spion.

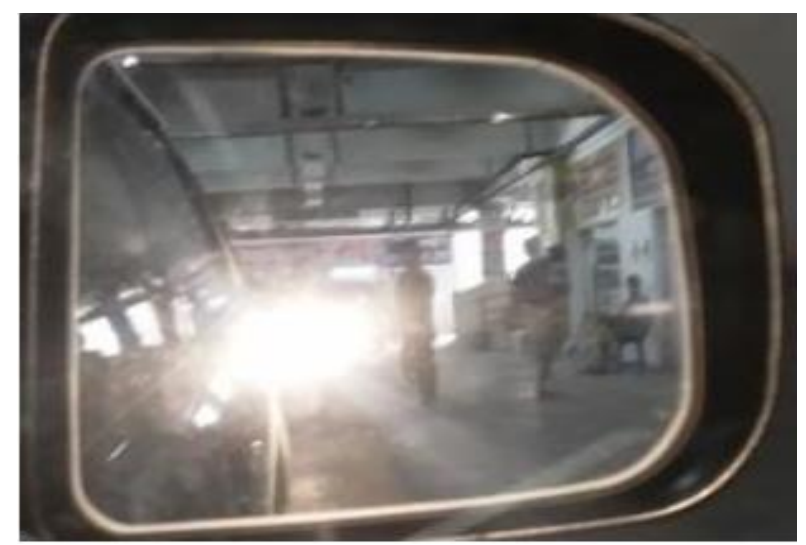

(a)



(b)

Gambar 9. Kemampuan mengolah cahaya: (a) kamera dengan lensa $8 \mathrm{~mm}$ dan (b) cermin spion.
CMS dengan lensa $8 \mathrm{~mm}$ memiliki field of view yang lebih lebar dan perbesaran yang mendekati cermin spion sebagaimana ditunjukkan Gambar 8. Field of view vertikal yang dihasilkan spion standar tampak lebih besar daripada sistem CMS. Hal ini disebabkan dimensi cermin yang besar dan ukuran sensor kamera yang tidak dioptimasi untuk penggunaan CMS. Perbedaan lain juga tampak pada detil gambar. Gambar yang dihasilkan oleh CMS menampilkan gambar lingkungan dengan detil yang lebih jelas.

Gambar 9 (b) menunjukkan kemampuan kamera CMOS dalam mengolah cahaya dari lampu besar kendaraan lain. Cahaya dari mobil lain tidak mempengaruhi penglihatan kamera karena sensor CMOS pada kamera yang digunakan dapat melakukan kompensasi cahaya pada objek di sekitarnya. Sedangkan pada Gambar 9 (a), cermin hanya memantulkan cahaya tanpa adanya pengolahan. Objek di sekitar sumber cahaya tampak gelap dan cahaya dipantulkan secara langsung sehingga hal ini dapat menyilaukan pengemudi.



(a)



(b)

Gambar 10. Gambar yang dihasilkan: (a) kamera dengan lensa $8 \mathrm{~mm}$ dan (b) cermin spion pada malam hari. 
Gambar 10 (a) dan 10 (b) menunjukkan perbedaan gambar yang dihasilkan spion standar dengan spion CMS. Dapat disimpulkan bahwa gambar yang dihasilkan oleh spion CMS lebih baik dibandingkan gambar yang dihasilkan oleh spion standar. Visibilitas gambar yang dihasilkan oleh spion standar bergantung pada jumlah cahaya yang dapat dipantulkan oleh cermin ke pengemudi, sedangkan pada spion CMS fitur wide dynamic range pada kamera dapat menciptakan gambar yang identik dengan berbagai tingkat pencahayaan yang kemudian digabungkan menghasilkan gambar dengan pencahayaan yang lebih seimbang.

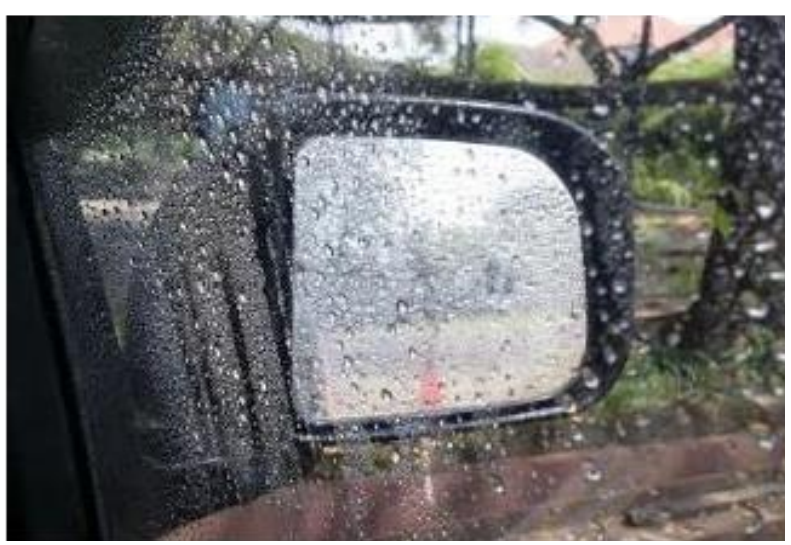

(a)



(b)

Gambar 11. Tetesan air mengurangi kualitas gambar pada: (a) kamera dengan lensa $8 \mathrm{~mm}$ dan (b) cermin spion.

Gambar 11 (a) menunjukkan gambar yang dihasilkan oleh cermin spion pada keadaan permukaan cermin basah. Kondisi ini ditemui pada saat kendaraan terkena air hujan. Cermin tidak dapat menghasilkan gambar yang baik dan objek pada cermin sulit untuk dikenali. Gangguan ini disebabkan oleh tetesan air di jendela samping pengemudi, lapisan air pada permukaan yang menyebabkan gambar kabur dan menghasilkan kondisi pengamatan yang lebih buruk. Gambar 11 (b) menunjukkan gambar yang dihasilkan oleh cermin CMS.
Tetesan air pada spion CMS hanya sedikit mempengaruhi gambar yang dihasilkan. Hal ini diakibatkan karena kamera hanya mentransmisikan gambar ke monitor, sehingga tetesan air pada jendela samping pengemudi tidak mempengaruhi gambar.

\section{KESIMPULAN}

Sistem CMS dapat digunakan sebagai pengganti cermin spion tanpa menyebabkan pengemudi merasa tidak nyaman karena field of view dan perbesaran yang dihasilkan kamera tidak jauh berbeda dengan spion standar. Peningkatan field of view sebesar $12.75 \%$ mereduksi blindspot yang terjadi pada spion standar. Delay yang dihasilkan spion CMS memenuhi batas maksimum delay yang diperbolehkan yaitu $200 \mathrm{~ms}$. Perancangan spion kamera ini merubah bentuk spion sehingga mereduksi frontal area spion tanpa merubah posisi pemasangan spion. Perubahan bentuk spion menghasilkan reduksi gayadrag sebesar $78.58 \%$.

\section{DAFTAR PUSTAKA}

[1]. Schumann, J., Sivak, M., Flannagan, M. J., 1996, Are Driver-Side Convex Mirrors Helpful or Harmful, University of Michigan Transport Research Institute, Ann Arbor, the United States of America.

[2]. Large, D. R., Crundal, E., Burnett, G., Harvey, C., Konstantopoulos, P., 2016, "Driving without wings: The effect of different digital mirror locations on the visual behaviour, performance and opinions of drivers", Applied Ergonomics, 55, pp. 138-148.

[3]. Ai, S. L. S., Al-Obaidi, A. S. M., Hong, L. C., 2016, "Effect of Size and Shape of Side Mirrors on the Drag of a Personal Vehicle", Proceeding of the International Engineering Research Conference (7th Eureca), Subang Jaya, Malaysia.

[4]. Murata, A., Kohno, Y., 2018, "Effectiveness of replacement of automotive side mirrors by invehicle LCD - Effect of location and size of LCD on safety and efficiency", International Journal of Industrial Ergonomics, 66, pp. 177-186.

[5]. Ali, J. S. Mohamed, Bazilah, F. F., 2014, "Mirrorless Car: A Feasibility Study", Applied Mechanics and Materials, 663, pp. 649-654.

[6]. Alves, R. M., Almeida, O., 2017, "Validation of Experimental and Numerical Techniques for Flow Analysis over an Ahmed Body", International Journal of Engineering Research and Applications, 7, pp. 63-71.

[7]. Terzis, A. (Ed.), 2016, Handbook of Camera Monitor Systems: The Automotive Mirror Replacement Technology based on ISO 1650, Springer, Switzerland. 